\section{LABOR DESARROLLADA POR EL INSTITUTO NACIONAL DE AHORRO Y VIVIENDA (INAV) EN LA HABANA (1959-1962)'}

Ruslan Muñoz Hernández², Gabriela González González ${ }^{3}$

\section{Resumen}

En 1959, se creó en Cuba el Instituto Nacional de Ahorro y Vivienda, INAV que funcionó hasta 1962. El quehacer constructivo de esa entidad marcó el punto de viraje dentro de la política habitacional cubana y constituyó el momento del despegue de la construcción a gran escala de la vivienda social. A partir de este momento la nación cubana se situó a la altura de sus similares en el contexto regional, a partir de un plan masivo e integral en su concepto. En el presente texto se resumen los resultados de una investigación de carácter histórico, basada en la consulta de fuentes primarias de información y trabajo de campo, complementada

\section{THE WORK OF THE NATIONAL INSTITUTE OF SAVINGS AND HOUSING (INAV) IN HAVANA (1959-1962) ${ }^{1}$}

Ruslan Muñoz Hernández², Gabriela González González $^{3}$

\section{Abstract}

The National Institute of Savings and Housing (INAV) was created in 1959 in Havana and operated until 1962. The constructive work done by this agency marked a turning point within the context of housing policies in Cuba and sparked a boom in the construction of large-scale social housing estates. From that moment on, Cuba was at the same level as its regional counterparts thanks to the development of a massive and comprehensive plan. This paper offers the results of research of a historical nature based on the collection of primary data, fieldwork 
con testimonios adquiridos mediante entrevistas a los fundadores o primeros beneficiados de este organismo, lo que permitió hacer el levantamiento, la clasificación y una primera caracterización de la obra desarrollada por el INAV en La Habana.

\section{PALABRAS CLAVES: VIVIENDA SOCIAL; PATRIMONIO DE LA AROUITECTURA MODERNA; AROUITECTURA HABITACIONAL EN LATINOAMÉRICA Y EL CARIBE; LA HABANA.}

Fecha de recepción: 12-11-2014

Fecha de aceptación: 05-06-2015

1 El documento es parte de un proyecto de investigación en desarrollo por la línea de estudios de la Vivienda Social de la Facultad de Arquitectura del ISPJAE, de La Habana. El proyecto se comenzó a desarrollar en el año 2010, se denomina: “Más de cien años de la vivienda social en Cuba", cuenta con el financiamiento de la propia universidad y se encuentra registrado con el nro. PR-0470. Investigador responsable: Dra. Arq. María V. Zardoya Loureda.

2 Cuba. Graduado de Arquitectura en el 2011 en el Instituto Superior Politécnico José Antonio Echeverría ISPJAE, La Habana. Profesor Instructor de la disciplina de Teoría, Crítica e Historia de la Arquitectura y el Urbanismo. Miembro del grupo de investigación de la vivienda social de la Facultad de Arquitectura del Instituto Superior Politécnico José Antonio Echeverría. Aspirante al grado de Máster en Vivienda Social. Correo electrónico: ruslan@arquitectura.cujae.edu.cu.

3 Cuba. Arquitecta, graduada del Instituto Superior Politécnico José Antonio Echeverría en el 2014. Correo electrónico: gabriela@arquitectura.cujae.edu.cu. and narratives obtained through interviews with the founders and first beneficiaries of this program. This allowed us to gather, classify and characterize the work done by the INAV in Havana.

KEYWORDS: SOCIAL HOUSING; HERITAGE OF MODERN ARCHITECTURE; HOUSING ARQUITECTURE IN LATIN AMERICA AND THE CARIBBEAN; HAVANA.
Accepted: 05-06-2015

1 This paper is part of a research project developed by the Social Housing department at the Faculty of Architecture, ISPJAE, Havana. This project, entitled "A Hundred Years on Social Housing in Cuba" PR-0470 began in 2010 and is funded by ISPJAE. Researcher in charge: Arch. Maria V. Zardoya Loureda, PhD.

2 Cuba. BA in Architecture, 2011, ISPJAE, Havana. Professor of Theory, Criticism and History of Architecture and Urban Planning. Member of the social housing research group at the Faculty of Architecture, ISPJAE. Master's student in Social Housing. Email: ruslan@arquitectura.cujae.edu.cu

3 Cuba. BA in Architecture, 2014, ISPJAE. Email: gabriela@arquitectura.cujae.edu.cu 


\section{Introducción}

Las obras del INAV no han sido superadas en calidad de ejecución y diseño por ningún otro plan de construcción de viviendas sociales desarrolladas en Cuba a lo largo de más de cincuenta años. El INAV se creó en febrero de 1959, y asumió una gran parte de la edificación de viviendas por el Estado cubano en el periodo de 1959 y 1962, con el fomento de nuevos repartos y el relleno de terrenos vacíos dentro de las ciudades de todo el país. Las "casas de Pastorita" llamadas así en honor de la presidenta de dicho organismo Pastora Núñez González, asimilaron el lenguaje del urbanismo y la arquitectura del Movimiento Moderno en la versión de la vivienda individual aislada en conjuntos pequeños y medianos y en unidades habitacionales conformadas por edificios multifamiliares ${ }^{4}$.

La obra del INAV ha sido reconocida por sus valores y trascendencia en el tiempo. En el año 2001 le fue conferido a Pastorita el Premio Cuadro de Honor, otorgado por la Building and Social Housing Foundation del Programa de las Naciones Unidas para los Asentamientos Humanos (UN-Hábitat), por sus resultados. Pero el mayor reconocimiento que ha alcanzado tanto el INAV como su directora,

$4 \quad$ Zardoya, 2012, p. 336. ha sido la identificación de los residentes de esos conjuntos y de la población en general a lo largo de medio siglo.

En diferentes textos ${ }^{5}$ que analizan el quehacer constructivo de los primeros años de la Revolución cubana, se aborda la labor de INAV. En general, se ha estudiado con bastante profundidad la Unidad Vecinal Camilo Cienfuegos, la obra más documentada de todas las realizaciones del instituto, que ha sido objeto de estudio además en trabajos de Diplomas y de Maestrías que analizan ese conjunto desde diferentes miradas. Sin embargo, se desconoce en gran medida el resto del universo creado por el INAV, tanto en La Habana como en toda Cuba. Con vistas a lograr un conocimiento más amplio del INAV en cuanto a su dimensión y alcance, sus realizaciones y sus protagonistas, se generó la necesidad de emprender esta investigación, que se planteó como objetivos: realizar un levantamiento, clasificación y una primera caracterización de la obra desarrollada por el INAV en La Habana en el período de 1959-1962. Sin embargo, por razones de extensión, el texto no se adentra en analizar en la producción residencial global del instituto en ese periodo, sólo es una primera mirada de como funcionó y se estructuró el INAV en el

5 Los textos más representativos son: Diez años de arquitectura en Cuba revolucionaria (1969), La vivienda en Cuba: República y Revolución (1979) y Arquitectura y Urbanismo de la Revolución Cubana (1989), todos escritos por Roberto Segre. 
escenario de fuertes cambios sociopolíticos en que se desarrolló.

La presente investigación de carácter histórico, partió de hipótesis de reconstrucción histórica que fueron validadas y/o reajustadas tras el procesamiento de la información recopilada en la documentación de archivo con la consulta e interpretación de valiosas fuentes primarias de información (las memorias económicas del INAV Presencia del INAV en la Revolución Cubana ${ }^{6}$ y los planos del fondo del propio instituto en el Archivo Nacional de Cuba, además de la prensa de la época y revistas especializadas). Una vez identificado el universo objeto de estudio, se realizó en paralelo un trabajo de campo, lo que permitió clasificar y caracterizar la muestra de estudio y realizar los análisis cuantitativos y cualitativos. Lamentablemente no se pudo entrevistar a los proyectistas que protagonizaron esta hazaña ya que la mayoría han fallecido o no radican en Cuba.

Entre las variables analizadas se encuentran los antecedentes históricos de la vivienda social en Cuba y el propio contexto sociopolítico del triunfo de la Revolución que identificó la labor del INAV. Entre las variables urbanas y arquitectónicas fueron analizados el emplazamiento geográfico de las obras, y sus tendencias formales y espaciales. Este trabajo pretende llenar un vacío en la historia de la

6 El texto de 848 páginas recoge todo lo realizado por el INAV en el país. Abarca desde el 20 de marzo de 1959 hasta junio de 1961. arquitectura y el urbanismo cubano de los años 60 , pues constituye el primer estudio específico de la experiencia del INAV, lo que permite comprender mejor la arquitectura cubana de esos años.

\section{La preocupación por la vivienda}

La relación entre el Estado y los planes de desarrollo habitacional ha variado en el tiempo, de hecho a partir de la segunda mitad del siglo XX y con mayor fuerza en las últimas décadas ya no se habla de vivienda social, sino más bien de la vivienda de interés social, aplicado a los programas orientados hacia los sectores de bajos ingresos de la población, que no tienen acceso al mercado formal de la vivienda y que generalmente, se ubica en asentamientos informales precarios. A los efectos de este trabajo, teniendo en cuenta que el objeto de estudio en la producción habitacional del INAV se entiende como vivienda social "aquella vivienda promovida, producida y gestionada por el estado $u$ otros patrocinadores y destinada a la población que no cuenta con los ingresos suficientes para adquirirla en el mercado" ". Por otra parte, en los países de habla hispana, se emplean indistintamente diferentes términos como el de "vivienda colectiva" para referirse también al edificio de apartamento,

$7 \quad$ Gelabert, 2010, p. 7. 
muy relacionado con el inicio del Movimiento Moderno ${ }^{8}$.

La preocupación por la solución del problema de la vivienda masiva para una clase social mayoritaria que no podía acceder por sus medios a una vivienda digna surgió por primera vez en la Europa del siglo XIX ante el peligro que constituía la nueva clase obrera urbana, que habiendo emigrado del campo en busca de trabajo, se asentaba en pésimas condiciones de habitabilidad alrededor de las industrias, esto además despertó preocupaciones higienistas que repercutieron en el hábitat en general, dando paso a las primeras comunidades obreras europeas ${ }^{9}$.

En un contexto general, la discusión efectuada en torno al problema social y en particular al de la vivienda obrera a fines del siglo XIX, constituye un registro esencial para aproximarse a los procesos políticos y sociales que dieron lugar a la generación de iniciativas para enfrentar dicha situación. Desde mediados del siglo ya algunas naciones impulsaron iniciativas legales con medidas para mejorar las condiciones higiénicas, fundamentalmente de las nuevas viviendas que se construían, entre ellas la promulgación de la Public Health Act (1848) en Londres, y los Traite de la salubrité dans les grandes villes, de Francia. También en España siguiendo los

8 AAVV, 2007, p. 10.

9 González Couret, 2006, p. 57-62. pasos de sus vecinos surgió la Constructora Benéfica (Madrid, 1875) con la ejecución de viviendas para los más necesitados ${ }^{10}$.

A finales del siglo el problema de la vivienda se había convertido en una cuestión política de primer orden, como parte, en muchos casos de las reivindicaciones de los primeros parlamentarios de la izquierda europea. Los estados de opinión llevaron a celebrar en 1889 en París el Primer Congreso Internacional de Casas Baratas ${ }^{11}$. La presión social en diferentes países europeos obligó a la aprobación de leyes para el fomento de la vivienda social como la London County Council 1888) y la Housing of Working Classes Act (1890) de Inglaterra; la sociedad HBM (Habitatlons á bon marché) de Francia, en el año 1889, mientras que en España la tensa situación llevó al gobierno a emitir la primera legislación sobre la materia, la Ley de Casas Baratas de $1911^{12}$.

En el siglo XX los escenarios fueron más complejos marcados por dos momentos transcendentales en la relación entre la vivienda social y relacionados con las transformaciones que apuntaron hacia lo que hoy llamamos Movimiento Moderno. El primer momento estuvo caracterizado por las experimentaciones del periodo de entreguerras con los modelos erigidos en las grandes ciudades alemanas y

\footnotetext{
10 López, 2003.

11 Barreiro, 1991, citado en Hidalgo, 2002.

12 Diez-Pastor, 2003.
} 
soviéticas, en Viena o en los nuevos barrios holandeses; y el segundo con las teorías recogidas en los primeros CIAM; y concluida la II Guerra Mundial en la paradigmática Unité d' Habitation (Marsella, 1946-52). Estos dos momentos tan significativos, no son sólo el reflejo de una transformación en la arquitectura, sino una respuesta a los profundos cambios socioeconómicos del siglo XX. La intervención del Estado se ejerció de dos formas: mediante créditos y facilidades concedidas a las asociaciones privadas y a través de la construcción de viviendas por iniciativa directa de empresas públicas.

\section{La influencia continental}

La obra constructiva del INAV materializó en Cuba mucho de lo que se debatió y teorizó en los congresos Internacionales de Arquitectura de los años treinta al cincuenta del siglo XX a nivel continental sobre el derecho de los obreros a una vivienda higiénica y económica, las políticas en favor de la vivienda de social, la disyuntiva entre la vivienda aislada y el crecimiento en altura y el financiamiento de las obras.

El contexto latinoamericano constituyó un referente directo para Cuba en materia de vivienda social pues su influencia se reflejó a través de las publicaciones especializadas y la celebración de los cónclaves regionales de arquitectura. Entre 1930 y 1960, las naciones latinoamericanas experimentaron no sólo cambios, sino que aportaron novedosas respuestas a problemas de la vivienda nunca antes planteados.

La crisis capitalista de 1929-1933 abrió una nueva etapa en la historia de América Latina. Sus consecuencias no solo trascendieron en el ámbito económico sino que repercutió también en la estructura social, al propiciar la emigración del campo a la ciudad. Al calor de los efectos de la depresión, y de determinados factores internos propios en cada caso, florecieron entre los años veinte y treinta en la región varios movimientos nacionalistas, sublevaciones populares, revueltas campesinas y fallidos intentos revolucionarios que estremecieron el continente de un extremo a otro. En naciones como Chile, Argentina, Brasil, México, Venezuela y Colombia, los sectores emergentes, que representaban los intereses de la naciente burguesía nacional, alcanzaron o compartieron el poder e impusieron nuevas políticas orientadas a promover el desarrollo interno sobre la base de una serie de medidas proteccionistas y nacionalistas, típicas de capitalismo de estado ${ }^{13}$. Por otra parte, a partir de los años treinta se evidenció un significativo crecimiento de las organizaciones de izquierda, de las fuerzas obreras y del movimiento democrático en toda la región obligando a las oligarquías a restablecer las

13 Guerra, 2010, p. 234. 
libertades democráticas y satisfacer otras reivindicaciones sociales de envergadura ${ }^{14}$.

En las naciones antes mencionadas, la presión social y el contexto político obligaron a definir nuevos sistemas legislativos y mecanismos financieros que posibilitaran acceder a la vivienda, modificar las políticas de suelo, y propiedad inmobiliaria, en aras de crear oficinas estatales de proyectos capaces de desarrollar planes nacionales de vivienda. Muy temprano, durante la última década del siglo XIX se presentaron en Chile al menos siete proyectos de Ley para la Promoción de Viviendas Económicas, aprobándose en 1906 la Ley de Habitaciones Obreras y la Ley de Habitaciones Baratas de $1925^{15}$ y en 1915 se constituía en Argentina la Comisión Nacional de Casas Baratas ${ }^{16}$. De manera progresiva los Estados fueron adquiriendo más compromiso con el problema habitacional. Intervino fijando normas de construcción, fomentó la intervención del sector privado, promovió la creación de cooperativas de vivienda, reguló las rentas mediante las leyes de Congelación de Alquileres buscando proteger a la población de los especuladores, y por último comenzó a construir directamente nue-

\footnotetext{
14 Ibid., p. 247.

15 Hidalgo, 2002.

16 Aboy, 2012, p.74.
}

vos lugares de alojamiento para la población más necesitada.

El papel de grandes instituciones como la Corporación de la Vivienda (CORVI), en Chile (1952) ${ }^{17}$, el Instituto Nacional de la Vivienda en México en $(1954)^{18}$, el Taller de Arquitectura del Banco Obrero en Venezuela (TABO entre 1954 y 1958) ${ }^{19}$, los Institutos de Jubilaciones y Pensiones IAPs, en Brasil $^{20}$, entre otros, así como un gran número de entidades bancarias y financieras que apoyaron la construcción de grandes planes habitacionales han sido abordadas en diferentes estudios ${ }^{21}$ que coinciden en valorar y considerarla obra de estos organismos como parte del patrimonio arquitectónico habitacional latinoamericano del siglo XX.

En estos países se abrió el doble debate de transformar la ciudad y definir una política de vivienda, entendiendo uno en función del otro, ideas que fueron expuestas en los diferentes escenarios internacionales. En el IX Congreso Panamericano de Arquitectos celebrado en Caracas en 1955 se abogó por la necesidad de crear Ministerios o Secretarias de vivienda y urbanismo ${ }^{22}$, así como la creación del Banco Privado Interamericano de

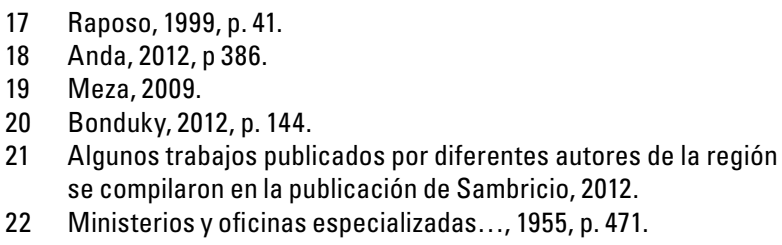


Fomento a la Vivienda de Interés Social ${ }^{23}$. También desde los Estados Unidos, la labor de la Public Housing Authority, (PHA), especialmente de la New York City Housing Authority (NYCHA) creada en 1936, fue divulgada a través de la revista cubana Arquitectura, en el marco del XV Congreso Internacional de Arquitectos que tuvo como sedes a Washington y Nueva York en el año $1939^{24}$.

Uno de los temas abordados en diversos espacios fue el concepto de "unidad vecinal" y el crecimiento en altura como alternativas a la influencia del modelo de las ciudades jardín anglosajonas, ampliamente difundido en el continente. Los debates en torno a la "unidad vecinal" se centraron en la importancia que ésta tenía, al ser elemento constitutivo de un conjunto que compete los niveles: urbano, regional y nacional. El concepto de unidad vecinal, ligado a una fórmula de equipamiento racionalizado como función del Estado, tuvo una amplia difusión en la región, ya desde la década de los 40. El principio de entender a la "unidad vecinal" como un conjunto integrado de edificios, servicios, instalaciones y espacios sociales, conllevó tanto al arquitecto como al urbanista asumir otras concepciones estéticas y funcionales de panificación urbana ${ }^{25}$. Las influencias del urbanismo y la arquitectura racionalista se asumieron con mucha fuerza y aunque varias realizaciones adoptaron los postulados del CIAM, la experiencia continental trató de superar el esquema del bloque a aislado con tipologías cerradas y carácter anodino que marcó la imagen de muchas de las prácticas europeas en un primer momento.

\section{Antecedentes. La vivienda social en La Habana durante el periodo republicano (1902- 1958)}

Los primeros criterios sobre la vivienda social en Cuba comenzaron desde inicios del siglo XX. Los temas higienistas relacionados con el hábitat, despertaron el interés de médicos, periodistas, y arquitectos quienes a través de los medios de prensa, incluyendo la revista Arquitectura, órgano oficial del Colegio Nacional de Arquitectos, reflejaban sus preocupaciones. Los principales voceros fueron los arquitectos Pedro Martínez Inclán y Luis Bay Sevilla, quien luchó incansablemente por viabilizar una Ley sobre casas baratas, aspiración recogida en su libro La vivienda del pobre de 1924. Otras importantes contribuciones al tema las hicieron los arquitectos José María Bens Arrarte y Manuel

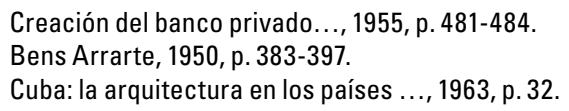


Febles Valdés desde su posición de Ministro de Obras Públicas ${ }^{26}$.

A lo largo del periodo republicano, las iniciativas estatales fueron insuficientes debido a la falta de voluntad política para llevarlas a cabo. Sólo se realizaron alrededor de 950 casas en el barrio Redención conocido como Barrio de Pogolotti en Marianao entre 1911 y $1912^{27}$. En los años veinte, surgieron algunas iniciativas aisladas y de poco impacto promovidas por cooperativas de obreros.

En 1945 el Patronato Pro Urbanismo de Cuba organizó una exposición de las experiencias materializadas enel tema en otros países de la región latinoamericana ${ }^{28}$. Esto influyó en que la prensa promoviera los criterios sobre la necesidad de crear barrios obreros. Ante este escenario comenzó la construcción del "Barrio Residencial Obrero de Luyanó" en La Habana durante el gobierno del presidente Ramón Grau San Martín en 1947 y concluyó en 1953 en el gobierno del presidente Fulgencio Batista, quien le sustituyó el nombre por el de "Reparto Aranguren" para quitarle su significación proletaria ${ }^{29}$ (figura 1). Esta experiencia constituyó la única realización a escala urbanística de gran envergadura, de un conjunto de viviendas económicas realizado en Cuba en medio siglo.

26 Peñate, 2011, p. 36.

27 Zardoya, 2012, p. 318.

28 Peñate 2011, p. 40.

29 República de Cuba, 1954.
Posterior a esta obra le sucedieron otras experiencias esbozadas desde concursos que quedaron solamente en proyectos. Paralelo a ello se encontraban las cooperativas pensadas ya desde antes. Una de las experiencias de este tipo fue la emprendida por la Cooperativa de Repartos Eléctricos de empleados, de la Compañía Cubana de Electricidad.

A la vez, en 1946 se promulgó una ley con el mismo nombre que la propuesta por Bay Sevilla ocho años atrás, Ley de Casas Baratas, pero muy diferente de aquella que no modificó en nada la crisis existente $^{30}$. A pesar de que en 1939 se había anunciado el propósito de crear en las naciones latinoamericanas una Comisión Nacional de la Vivienda, durante el Primer Congreso Panamericano de Arquitectos celebrado en Buenos Aires no fue hasta octubre de 1950 que dicha comisión fue creada en Cuba y presidida por el propio Febles Valdés, entonces Ministro de Obras Públicas.

La falta de solución a los problemas de la vivienda popular al terminar el período republicano no fue por inexperiencia y desconocimiento, ya que se habían hecho estudios y propuestas que fueron divulgadas en la prensa, sino por el desinterés de los gobiernos. Los reclamos hechos por voces autorizadas abogando por la solución a estos males

30 Zardoya, 2012, p. 323. 
FIGURA 1: VISTA DEL BARRIO OBRERO DE LUYANÓ EN 1953

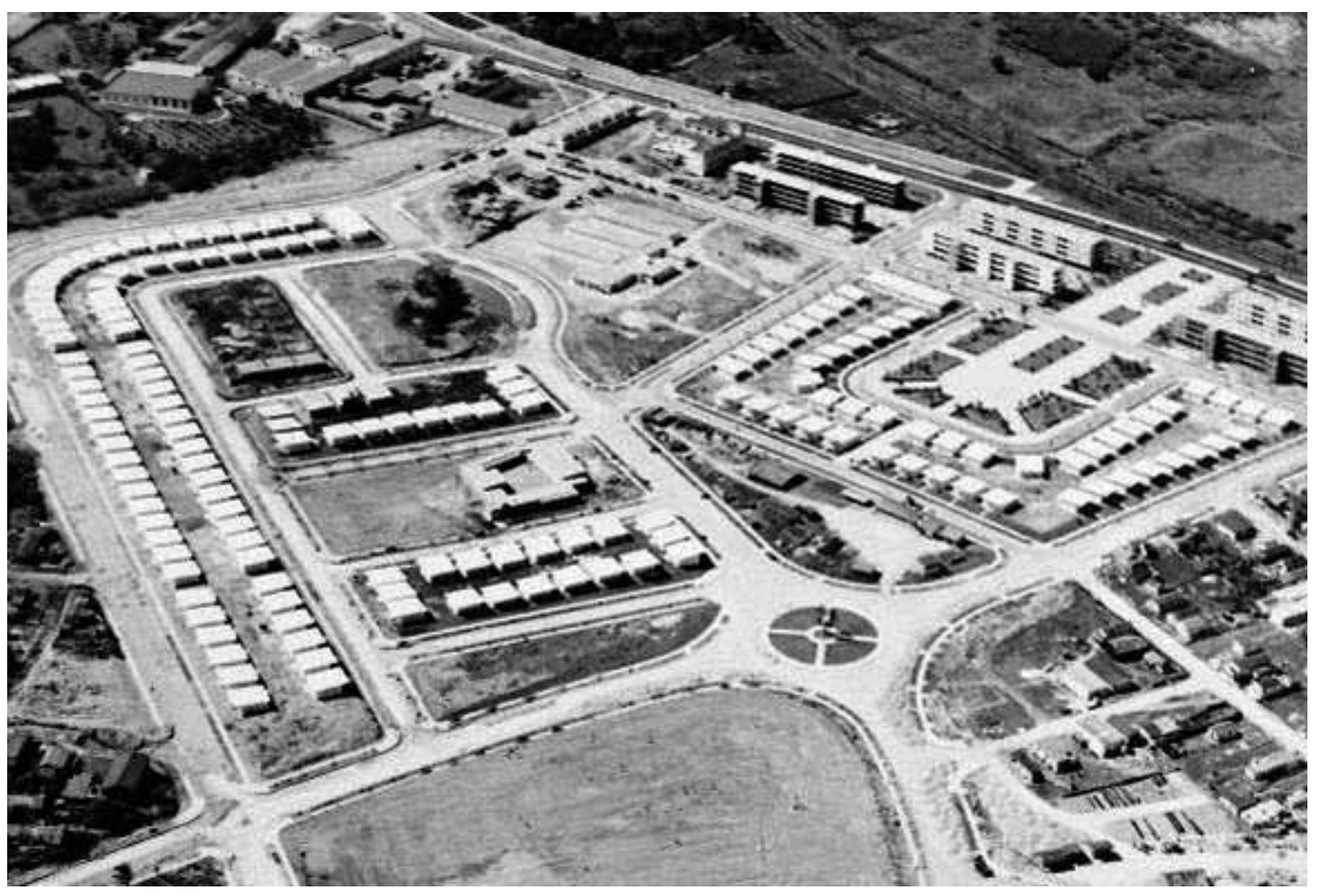

Fuente: Archivo del Ministerio de Obras Publicas (MOP). 
fueron apagadas por los fuertes intereses de los grupos dominantes ${ }^{31}$, negando la responsabilidad del Estado.

Por otra parte, este proceso fue sucediendo en paralelo a la asimilación del lenguaje del Movimiento Moderno, en el que los mejores arquitectos cubanos del momento: Max Borges, Mario Romañach, Frank Martínez, Manuel Gutiérrez, Antonio Quintana, Lanz y del Pozo, reinterpretaron los valores de la arquitectura tradicional, y adoptaron las mejores soluciones favorables para el clima cubano fusionadas con las experiencias de los arquitectos de renombre internacional.

En Cuba la arquitectura del llamado Movimiento Moderno no fue la obra de una constelación de estrellas, desconectada del resto de los proyectistas con una acción más teórica que práctica, por el contrario, fue un quehacer muy prolífico que se extendió a todos los temas arquitectónicos y clases sociales, asimilado casi por consenso unánime. Si bien con la llegada de la Revolución Cubana se produjeron drásticos cambios estructurales en todos los ámbitos de la sociedad, en lo referente a la arquitectura hubo una continuidad desde el punto de vista formal y expresivo hasta finales de la

31 Se encuentran en estos grupos los "casatenientes", llamados así a los dueños de varios inmuebles destinados a la renta, también se incluyen políticos corruptos que privilegiaban a los propietarios de terrenos urbanos de alto valor. década del sesenta. Precisamente el quehacer del INAV se insertó en este momento de tránsito.

\section{El momento del cambio}

Con la llegada del año 1959 se sucedieron radicales cambios políticos y sociales que modificaron el panorama constructivo del país. Con el triunfo de la Revolución cubana, la creación del INAV marcó el punto de viraje dentro de la política habitacional en el país y constituyó el momento del despegue de la construcción a gran escala de la vivienda social. A diferencia de sus vecinas naciones en que las empresas del Estado instrumentaron planes y estrategias de desarrollo de viviendas de forma masiva e integral en su concepto, en el caso cubano no había sido posible hasta ese momento, por lo tanto fue necesaria una revolución radical que cambiara la realidad de entonces.

Para implementar políticas encaminadas a la solución de la vivienda social y masiva, fue necesario transformar la estructura legal que favorecía hasta ese momento a la burguesía propietaria de inmuebles y terrenos. El 10 de marzo de ese mismo año se aprobó la Ley No 135 que rebajó los alquileres de las viviendas en un 50\% cuando no excedían de cien pesos, un 40\% cuando no llegaban a 
doscientos pesos ${ }^{32}$ y un $30 \%$ cuando fueran mayores de doscientos pesos ${ }^{33}$. El 7 de abril fue aprobada la Ley $\mathrm{N}^{\circ} .218$, de diciembre del propio año, la que fijó el precio a los solares yermos, lo que eliminó la especulación sobre el suelo.

De igual manera, se procedió a la nacionalización de las compañías constructoras privadas y extranjeras, terminado así el negocio inmobiliario y el concepto de la vivienda como mercancía. Este primer periodo se cerró con la ley de Reforma de Urbana (octubre 1960), la que otorgó el derecho de propiedad de la vivienda a todos los inquilinos mediante la amortización mensual del valor de ésta, y la expropiación e indemnización del original propietario. Su rango constitucional manifestó la decisión radical del gobierno de otorgarle la más alta jerarquía política y legislativa ${ }^{34}$.

Entre 1959 y 1963 diversos organismos del Estado cubano acometieron la planificación y construcción de viviendas, un amplio universo de alternativas a las que se suma las obras del INAV, que puede confundir al no saber discriminar bien los límites de actuación de cada una de ellas. En 1960 se creó la Dirección de Viviendas Campesinas, anexa al Instituto Nacional de Reforma Agraria (INRA), la

32 En Cuba, el peso cubano y el dólar estadounidense eran equivalentes y circulaban ambas para las operaciones financieras y comerciales. Fuente: Almanaque mundial de Selecciones Reader's Digest, 1956, p. 88.

33 Bell Lara, 2006, p. 133.

34 Estévez Curbelo, 1959.
Dirección de Viviendas Urbanas del Ministerio de Obras Públicas (MOP) se creó en 1961, nombrado posteriormente Ministerio de la Construcción (MICONS), la Junta Nacional de Planificación Revolucionaria y el ejército Rebelde ${ }^{35}$. También coexistieron con estos planes otras experiencias como los Programas de Ayuda Mutua y de Esfuerzo Propio, asociadas a la erradicación de las barriadas insalubres urbanas desde el año $1959^{36}$. Cada uno de estos programas respondió a diferentes estrategias trazadas dentro de una misma política habitacional y de planificación urbana y territorial del país. La instrumentación de estos planes contribuyó exponencialmente al desarrollo social y económico de vastos territorios, mientras que en el caso de las áreas urbanas centrales, sirvió para densificar áreas que habían quedado vírgenes a la llegada del año 1959 e integrarlas al tejido urbano existente.

En este periodo, no existió una estructura centralizada para la producción de viviendas, no obstante el INAV estableció orientaciones y normas que fusionaba los estándares de viviendas económicas artesanales en manos de empresas contratistas privadas y trabajadores autónomos, junto con la producción de viviendas por las empresas del Estado.

35 Segre, 1989, p. 66.

36 Cuba: la arquitectura en los países ..., 1963, p. 82. 
Se subraya además que en paralelo se desarrollaban modos de colaboración entre el INAV y el Colegio de Arquitectos, destinados a orientar el trabajo de los profesionales del gremio hacia la concepción y elaboración de modelos y soluciones técnicas y constructivas de vivienda popular urbana y rural. Para su mejor funcionamiento el instituto se apoyó en un sistema de administración y contratación de obras mediante la subasta pública a exigencia de la Asociación de Contratistas de Cuba ${ }^{37}$.

Las primeras experiencias de la semi-prefabricación llevadas a cabo por los otros programas estatales marcan la diferencia con el quehacer del INAV ya que en sus obras se siguieron empleando las técnicas tradicionales de la construcción. El hecho de no utilizarse la prefabricación en el instituto, respondió a sus propios mecanismos de gestión y construcción. En estos programas se mantuvieron los estándares máximos de calidad, sin embargo, la creatividad en la diversidad expresiva de los modelos, asumió un carácter diferente adecuado a la tecnología constructiva semi-prefabricada de entonces, por lo que la diferencia entre estas experiencias y las obras del INAV difieren en muchos sentidos.

37 Revolución. 2(97), 30 de marzo de 1959, p. 10.

\section{FIGURA 2: PASTORITA Y EL DISEÑADOR ELADIO RIBADULLA, AUTOR DEL DISEÑO DE LOS BONOS DEL INAV}

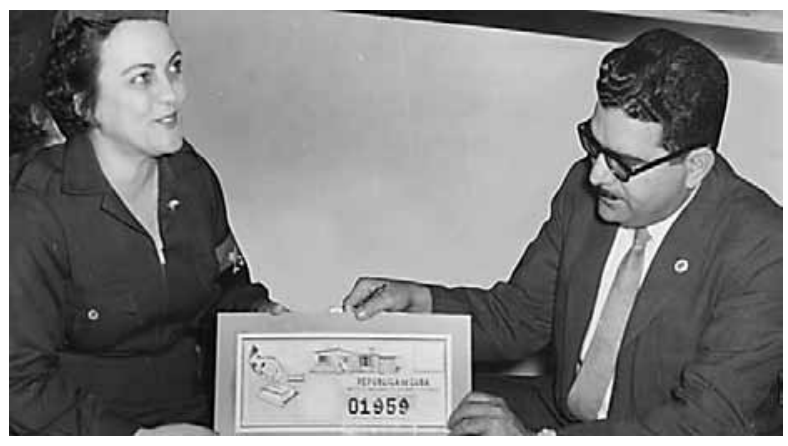

Fuente: Fernández Ferrer, 2011.

\section{EI INAV, su breve existencia}

La intención de crear el INAV, surgió en la Sierra Maestra por Fidel Castro en 1958. La idea era transformar la corrupta Renta de la Lotería Nacional en un instrumento para financiar la construcción de viviendas asequibles, convertir el juego en la virtud del ahorro, transformar los billetes en bonos y con lo ahorrado construir casas para el pueblo $^{38}$, consciente de que un mal hábito como el juego no podía ser eliminado por decreto, sino mediante el combate a las causas que lo fomentaban y una sistemática labor de educación.

38 Coyula, 2002, p. 184. 
Desde sus inicios, la Renta de la Lotería Nacional de Cuba constituyó durante toda la etapa republicana una fuente de corrupción y de enriquecimiento ilícito para quienes la administraban. Durante la dictadura de Batista, florecieron múltiples juegos de azar, los cuales se premiaban diariamente, mientras la lotería oficial lo hacía cada semana.

Para dirigir lo que sería el INAV fue nombrada por el propio Fidel Castro, Pastora Núñez y González, que se desempeñaba entonces como cobradora de impuestos del movimiento insurreccional contra Batista. El 17 de febrero de 1959 fue creado el Instituto Nacional de Ahorro y Vivienda (INAV) por la Ley No. $86^{39}$, ocupando el puesto de la Renta de la Lotería Nacional. Se transfirieron a dicho organismo todos los bienes muebles e inmuebles y demás pertenencias y derechos de la antigua Renta, como patrimonio inicial.

La producción de viviendas del INAV cesó en 1962 y las quedaron en proceso fueron traspasadas al nuevo organismo centralizador de todas las construcciones, el MOP. Sólo el INAV en los veintisiete meses de actuación hasta junio de 1962, en que la dirección de viviendas del instituto fue absorbida por el MOP, terminó 8,533 viviendas y entregó a dicha entidad otras 1,594 en proceso, en todo el país ${ }^{40}$. En tanto, el INAV siguió funcionando solamente como instrumento de ahorros bancarios.

39 Bell Lara, 2006, p. 115.

40 INAV, 1962

102 revista invi № 84 / Agosto 2015 / Volumen № 30: 89-120
Finalmente, en 1968, Fidel Castro se pronunció por la abolición definitiva del INAV al plantear:

"El INAV jugó un papel durante un tiempo como recaudador de impuestos, de recursos económicos en momentos en que había un montón de gente, con montón de dinero. No tiene sentido recaudar fondo de la gente que trabaja, de los trabajadores, eso lleva la idea de resolver los problemas mediante la suerte y no mediante el trabajo. El trabajo es el único que puede hacer rico a un pueblo"41.

El INAV, tal como se había previsto en su ley creadora, fue disuelto el 31 de marzo de $1968^{42}$.

\section{Política de actuación}

El trabajo del INAV se desarrolló en un convulso escenario de cambios, agresiones externas e internas contra el joven gobierno, y divisiones ideológicas, que conllevaron al éxodo masivo de cubanos que no comprendieron aquel proceso de necesarias transformaciones estructurales de la sociedad. Para el pueblo, el recién creado instituto y su política de actuación era completamente nuevo, por lo que se dedicó un ciclo de conferencias para explicar sus objetivos de programa y los beneficios que traería. La labor informativa de los medios de comunicación contribuyó a un mayor acercamiento entre el pueblo cubano y el INAV. Algunos diarios de la

\section{Castro, 1968}

42 Pérez, 1995, p. 82. 
época, como el Información y Revolución publicaban la mayoría de inauguraciones de las obras, y cada lunes se sacaban los ganadores de los sorteos y la relación de los adjudicados de las viviendas. También la radio y la televisión dieron cobertura a las tareas del instituto, programas como "Ganando y Ahorrando"43 o "Pregúntele a Pastorita"44, ambos transmitidos por CMBF-TV-Cadena Nacional y patrocinados por el propio INAV.

La política del INAV ideó la fórmula de que los billetes adquiridos para los sorteos de la Lotería no perdieran su valor, ni siquiera aquellos que no eran premiados, sino que se constituyeran en bonos de ahorro y capitalización de valor reintegrable. Pasados de cinco años, llegaban a tener el mismo valor por lo que la persona había pagado por él. Ello hizo posible que el sistema de juego se cambiará en un sistema de ahorro.

Los bonos sobrantes o nulos quedaban a cargo del INAV, quien se encargaba de hacerlos públicos antes de producirse el respectivo sorteo. El INAV tenía la potestad de aumentar el número de bonos, no así el importe fijado para premios, que sólo podía disminuirse hasta su supresión final, a medida que se iba aumentando la tendencia a conservarlos $^{45}$. Los sorteos eran públicos y semanales, y

43 Revolución. 2(314): 4, 11 de diciembre de 1959

44 Revolución, 2(203): 3, 3 de agosto de 1959.

45 Ley nro. 86 de 17 de febrero de 1959, art. 15. Fuente: Leyes del gobierno ..., 1959, p. 121-137. se celebraban en La Habana en el salón teatro del INAV ubicado primeramente en Ayestarán y 20 de Mayo, y posteriormente, en la calle Oficios $\mathrm{N}^{\circ} 154$, en la Habana Vieja ${ }^{46}$.

Al principio la tirada era de 40.000 bonos, en abril de 1959 fue de 50.000, después se fue reduciendo la cifra. El premio mayor era de 100 mil pesos, y los otros mil premios de cien pesos cada uno, por lo que se dedicaba 200 mil pesos para premios. Si en el sorteo habitual, el premio mayor correspondía a un número no vendido, este se acumulaba y se sorteaba en el siguiente previsto. Además se ofrecía el gran premio de estímulo al ahorro: 10 modernas casas de $\$ 5.000$ pesos cada una y mil premios de $\$ 50$ pesos $^{47}$.

El INAV se nutrió única y exclusivamente de las venta de bonos semanales, sin embargo aun así no podía satisfacer la demanda de viviendas por este concepto, por lo que sacó a la circulación una emisión de Certificados de Ahorro Popular, los que ofrecían un interés de un 7,5\% muy superior a los de cualquier otra cuenta de ahorro en ese momento, esto estimuló a los ciudadanos, a suscribirse de manera fija a este sistema, permitiendo obtener el doble de lo invertido en diez años y cuatro veces en veinte años ${ }^{48}$. Los certificados de ahorro fueron la

46 Pérez, 1995, p.80.

47 Revolución, 2(203), 3 de agosto de 1959.

48 Núñez, 1959, p. 15. 
contribución más significativa que hizo el pueblo al INAV, también apoyaron con fondos varias organizaciones de la sociedad civil, gremiales e incluso de algunos propietarios privados de terrenos.

\section{Financiamiento y formas de pago de las viviendas del INAV}

El proceso de la solicitud de las viviendas, se facilitó con el apoyo de trabajadores sociales quienes hicieron los estudios necesarios para que los beneficiados fueran familias verdaderamente necesitadas. La adjudicación de las viviendas por esta vía se daba a conocer a través de la prensa escrita y radial.

Las viviendas eran entregadas para su propiedad mediante planes de amortización que podían llegar hasta los treinta años, según el poder adquisitivo de la familia, aunque el término más frecuente fue de veinte años. El interés fluctuó desde el 1\% hasta el 5\%, no obstante para familias de muy pocos ingresos, el interés en ocasiones se eliminaba, asumiendo el Estado los déficits que pudieran existir. Los costos de viviendas construidas, con el terreno, instalaciones y gastos de administración, variaron de $\$ 4.500$ a $\$ 8.000$ pesos, sin embargo se proyectaron algunas construcciones más económicas, de hasta $\$ 2.600 .{ }^{49}$ Las casas con un valor mayor a $\$ 8.000$ se podían financiar a través del Fomento de Hipotecas Aseguradas (FHA) ${ }^{50}$, estas no eran fabricadas por el INAV ${ }^{51}$. Con el interés de erradicar los asentamientos precarios y tugurios de las ciudades cubanas en todas las provincias, proyectaron además, apartamentos mínimos como morada intermedia sin renunciar al confort, accesibles a familias con recursos limitados.

El 20 de febrero de 1960 al celebrarse el primer aniversario del INAV, fueron entregadas las primeras mil viviendas a sus propietarios de los recién terminados repartos del Wajay, El Trigal, Bahía y

49 Núñez, 1959, p. 10.

50 La ley de Fomento e Hipotecas Aseguradas (FHA) promulgada el 20 de marzo de1953 mediante el Decreto -Ley No. 750, también favoreció el auge constructivo que caracterizó la década de los cincuenta. Fue el organismo encargado de realizar préstamos hipotecarios vinculados al Banco de Fomento Agrícola e Industrial de Cuba (BANFAIC). Se hizo posible comprar con una entrada relativamente baja, tanto viviendas en edificios de apartamentos construidos con ese fin, como terrenos para la construcción de casas individuales en repartos suburbanos (Gómez, 2008, p. 344)

51 Arquitectura-Cuba. (318): 41-47, enero 1960. 
el Eléctrico, todos en La Habana. El acto fue celebrado en la sede del propio instituto, en el actual edificio del Ministerio de Economía y Planificación, con la presencia del primer ministro Fidel Castro, quien resaltó los éxitos del instituto y de sus protagonistas ${ }^{52}$.

\section{Los arquitectos}

El Colegio Nacional de Arquitectos, ante el llamado del gobierno, designó una Comisión de arquitectos, que fueron propuestos en asamblea, para la organización del Departamento de Viviendas del INAV. Dicho departamento se organizó en una Junta Directiva y a su vez en dos oficinas, una de Planeamiento Nacional que coordinaría la programación en todos los territorios y la otra de Finan$z_{a s^{53}}$. Para asumir esta inmensa tarea varios de los mejores profesionales que permanecieron en el país luego de 1959, nutrido por un grupo de jóvenes arquitectos deseosos de hacer, desempeñaron trabajos de todo tipo, desde dibujantes, ejecutores y calculistas hasta inversionistas, unidos por el compromiso con su labor social.

Los responsables de las obras a nivel nacional, fueron el arquitecto Cesáreo Fernández como Director General del Departamento de Arquitectura y Urbanismo y como Arquitecto Municipal de La

52 Castro, 1960.

53 Estévez, 1959, p. 154.
Habana; al frente del Departamento de Proyectos estuvo el arquitecto Manuel Labandero Rodríguez y el arquitecto Vicente Lanz como Vicedirector Técnico; en el Departamento de Estructura el arquitecto Nicolás de la Cova; en el Departamento de Presupuesto, la arquitecta Sara Pérez González y en Inspección de Obras el arquitecto Humberto Santo Tomas Valdivia. En Pinar del Rio estuvo al frente como Asesor técnico de la delegación provincial el arquitecto Conrado Fleites González, en Matanzas el arquitecto Servando Sánchez Pita; en Las Villas el arquitecto Manuel Moas Madrigal; en Camagüey el arquitecto German Scott Tapia y en la provincia de Oriente el arquitecto Rodulfo Ibarra Pérez ${ }^{54}$.

Como proyectistas estuvieron los arquitectos Modesto Campos, Juan Ignacio Guerra y Claudio Mendoza; Antonio Rojo y Lorenzo Gómez Fantoli; José A. Vila y Hilda Fernández Vila; Alberto Beales; Arq. Ernesto Gómez Sampera, Gonzalo Dean y Carlos Alfonso Díaz, Basilio Piasecki, María Elena Cabarrocas y Manuel Gutiérrez, Roberto Carrazana, Humberto Santo Tomás ${ }^{55}$, Margot del Pozo Seiglie, Heradia Hurtado Mendoza, Félix Pina Morgado, Mario González Cedeño, Selma Soto del Rey, Samuel Gutiérrez, Mercedes Díaz y Ana Vega.

Estos arquitectos fueron formados bajo la guía de profesores con una obra proyectual reconocida

54 INAV, 1962 p. 736

55 Concurso de ante-proyecto..., 1960, p. 144-150. 


\begin{tabular}{|c|c|c|c|c|}
\hline $\begin{array}{l}\text { Municipio antigua } \\
\text { (División política } \\
\text { - administrativa } \\
\text { vigente hasta 1976) }\end{array}$ & Municipio actual & $\begin{array}{l}\text { Repartos de } \\
\text { viviendas individuales }\end{array}$ & $\begin{array}{l}\text { Conjuntos de edificios típicos de } \\
\text { apartamentos }\end{array}$ & $\begin{array}{l}\text { Edificios de } \\
\text { apartamentos aislados y } \\
\text { atípicos }\end{array}$ \\
\hline \multirow[t]{3}{*}{ Guanabacoa } & \multirow[t]{3}{*}{$\begin{array}{l}\text { (parte del actual } \\
\text { Habana del Este) }\end{array}$} & $\begin{array}{l}\text { Residencial “Vía } \\
\text { Túnel”, }\end{array}$ & \multirow[t]{3}{*}{$\begin{array}{l}\text { Unidad Vecinal nro. } 1 \text { (“Ciudad } \\
\text { Camilo Cienfuegos") }\end{array}$} & \\
\hline & & Antonio Guiteras & & \\
\hline & & Eduardo Chibás & & \\
\hline \multirow[t]{5}{*}{ La Habana } & \multirow[t]{3}{*}{$\begin{array}{l}\text { (parte del actual } \\
\text { Plaza de la } \\
\text { Revolución) }\end{array}$} & & $\begin{array}{l}\text { Conjunto "Centro Cívico" calles } \\
\text { Ave. Colón, Hidalgo, Lombillo, } \\
\text { Estancia, San Pedro y Marino }\end{array}$ & $\begin{array}{l}\text { Edificio “Ñico López" } \\
\text { calle } 2 \text { e/ Línea y 11, } \\
\text { Vedado }\end{array}$ \\
\hline & & & & $\begin{array}{l}\text { Edificio “Ramón López y } \\
\text { Marcelo Salado", calle } 15 \\
\text { y 8, Vedado }\end{array}$ \\
\hline & & & & $\begin{array}{l}\text { Panorama e/ Tulipán y } \\
\text { Conill, Nuevo Vedado }\end{array}$ \\
\hline & \multirow{2}{*}{$\begin{array}{l}\text { (parte del actual } \\
\text { Cerro) }\end{array}$} & & Calles Sitios y Ayestarán & \\
\hline & & & $\begin{array}{l}\text { Calzada de Buenos Aires y } \\
\text { Durege }\end{array}$ & \\
\hline \multirow[t]{3}{*}{ Marianao } & $\begin{array}{l}\text { (parte del actual } \\
\text { Marianao) }\end{array}$ & & $\begin{array}{l}\text { "Los Pocitos" calles 126, 128, } \\
51 \text { y } 63\end{array}$ & $\begin{array}{l}\text { Edificio “Hugo Camejo” } \\
\text { calle } 57 \text { e/ } 144 \text { y } 146\end{array}$ \\
\hline & \multirow[t]{2}{*}{$\begin{array}{l}\text { (parte del actual } \\
\text { Playa) }\end{array}$} & & & $\begin{array}{l}\text { Edificio calle 7ma e/ } 114 \text { y } \\
\text { 116, Rpto. La Playa. }\end{array}$ \\
\hline & & $\begin{array}{l}\text { Reparto “Juan } \\
\text { Manuel Márquez", } \\
\text { Nuevo Santa Fé }\end{array}$ & & \\
\hline \multirow[t]{7}{*}{$\begin{array}{l}\text { San Antonio de las } \\
\text { Vegas }\end{array}$} & \multirow[t]{4}{*}{$\begin{array}{l}\text { ( actual Arroyo } \\
\text { Naranjo) }\end{array}$} & & $\begin{array}{l}\text { Bloques de apartamentos “ } \\
\text { Rpto. Poey" calle 2da. }\end{array}$ & \\
\hline & & Reparto Capri & & \\
\hline & & Reparto el Trigal & & \\
\hline & & Reparto Eléctrico & & \\
\hline & \multirow[t]{3}{*}{ (actual Boyeros) } & $\begin{array}{l}\text { Residencial INAV, } \\
\text { Nuevo Wajay }\end{array}$ & & \\
\hline & & $\begin{array}{l}\text { Reparto “Roberto } \\
\text { Negrín", Ampliación } \\
\text { del Wajay }\end{array}$ & & \\
\hline & & $\begin{array}{l}\text { Reparto “Calixto } \\
\text { Sanchez", Aéreo. }\end{array}$ & & \\
\hline Total & & 10 (1583 viviendas) & 6 & 5 \\
\hline
\end{tabular}

Fuente: Elaboración propia a partir de INAV, 1962 
TABLA 2. RESUMEN DE LAS OBRAS REALIZADAS EN LA HABANA ENTRE 1959 Y 1960, LAS OBRAS TRASPASADAS AL MOP FUERON TERMINADAS EN 1962

\begin{tabular}{llll}
$\begin{array}{l}\text { Total de casas construidas } \\
\text { por el INAV }\end{array}$ & $\begin{array}{l}\text { total de casa adjudicadas } \\
\text { por el INAV }\end{array}$ & $\begin{array}{l}\text { Total de casas entregadas } \\
\text { por el INAV a la CTC-R }\end{array}$ & $\begin{array}{l}\text { Obras en proceso } \\
\text { traspasadas por el INAV al } \\
\text { MOP para su terminación }\end{array}$ \\
\hline 5,921 & 3,146 & 1,685 & 820 \\
\hline
\end{tabular}

Fuente: Elaboración propia a partir de INAV, 1962.

dentro de la arquitectura del Movimiento Moderno cubano, mientras que algunos ya habían trabajado en oficinas prestigiosas de profesionales cubanos, por lo que en la obras del INAV, se da una continuidad de lo mejor de arquitectura moderna del país. Existió una alta calidad constructiva en la ejecución de las obras, realizadas por excelentes obreros y especialistas, desde los más sencillos y anónimos hasta grandes contratistas de prestigio en el país; Constructora FOCSA, S.A; Valls y Cabarrocas; Cía. Constructora Jaime Canavés S.A; José Menéndez, Armando Puentes entre otras.

\section{El INAV en La Habana}

La Habana concentró alrededor del setenta por ciento de la obra construida por el INAV en todo el país. A partir de la investigación realizada se ha dividido el objeto de estudio en repartos de viviendas aisladas, conjuntos de edificios multifamiliares y edificios atípicos en lotes aislados en la ciudad.

\section{La vivienda individual en los repartos suburbanos de La Habana y su continuidad en el INAV}

En Cuba también se manejó la dualidad de los debates sobre la adopción de viviendas aisladas o crecer en altura en edificios multifamiliares. Aunque gran parte de la clase media cubana, por razones económicas, se vio obligada a vivir en los edificios de apartamentos, la vivienda individual constituyó para este sector social, la máxima aspiración, el objetivo soñado y ambicionado, la concreción del bienestar y la seguridad de una posición social; no es casual que varias empresas fabricantes

56 CTC-R: Central de Trabajadores de Cuba Revolucionaria. 
de productos de consumo, organizaron sorteos y premios con el aliciente de una vivienda prototípica, totalmente amueblada ${ }^{57}$-algo que el propio INAV abolió mediante decreto- ${ }^{58}$. La presencia del automóvil, los bajos precios de los terrenos de la periferia urbana y las facilidades que ofrecían las empresas urbanizadoras, fueron razones que estimularon la preferencia por la vivienda aislada. Mientras, la opción de crecer verticalmente acelerada por la Ley de Propiedad Horizontal de 1952, fuese reservada para las zonas centrales consolidadas de la ciudad.

El modelo soñado y estereotipado de la vivienda individual se repitió, no sólo en Cuba sino en toda América Latina, codiciado más aun para los grupos proletarios que en su inmensa mayoría habían sido confinados a vivir en viviendas y cuarterías precarias en los centros urbanos. El INAV, a diferencia de sus homólogos latinoamericanos en que optaron generalmente por la tipología del bloque aislado en grandes conjuntos y unidades vecinales, le dio continuidad al patrón de la vivienda aislada como paradigma a seguir en un discurso de clase media, en el que las nuevas masas de trabajadores antes excluidas y sin la posibilidad de acceder a una vivienda digna, vieron materializar sus esperanzas con las facilidades que le ofreció esta entidad. En La Habana las unidades de apartamentos representan el grueso de la obra del instituto con el $66 \%$ de lo realizado y las viviendas aisladas el $34 \%$, mientras que a nivel nacional, sucede lo contrario. Por otro lado, debido a los propios mecanismos de gestión del INAV, basado en un sistema de administración y contratación de obras mediante la subasta pública, la forma más fácil, rápida y barata fue la opción de la vivienda aislada, frente a la complejidad y encarecimiento que representaban los edificios de apartamentos.

Entre las primeras tareas del INAV estuvo por un lado, el completamiento de urbanizaciones existentes desde finales de los años cincuenta, unas con un grado de ocupación mayor que otras, y por lo tanto fue necesario terminar lo que aún faltaba por ejecutar: infraestructura técnica, pavimentación de viales y aceras, áreas de parques, zonas de servicios comunales y escuelas. De igual forma, se construyeron otros repartos en su totalidad en la periferia de La Habana como el "Calixto Sánchez" en Boyeros, el "Roberto Negrín" en el Wajay y el "Juan Manuel Márquez" en Santa Fé, siguiendo los patrones de los repartos de la clase media, dotados de todos los servicios comunales.

A nivel nacional, el INAV diseñó y construyó más de cien modelos de viviendas individuales aisladas que variaron entre los $55 \mathrm{~m}^{2}$ y $153 \mathrm{~m}^{2}$, desde dos hasta cinco habitaciones, uno o dos baños y demás

57 Segre, 1979, p. 19.

58 El INAV aprueba decreto..., 1959, p. 51. 
FIGURA 3. ARRIBA: VIVIENDAS CONSTRUIDAS EN EL REPARTO CAPRI. DEBAJO: PLANTA DE UNO DE LOS 46 MODELOS EJECUTADOS EN LA HABANA
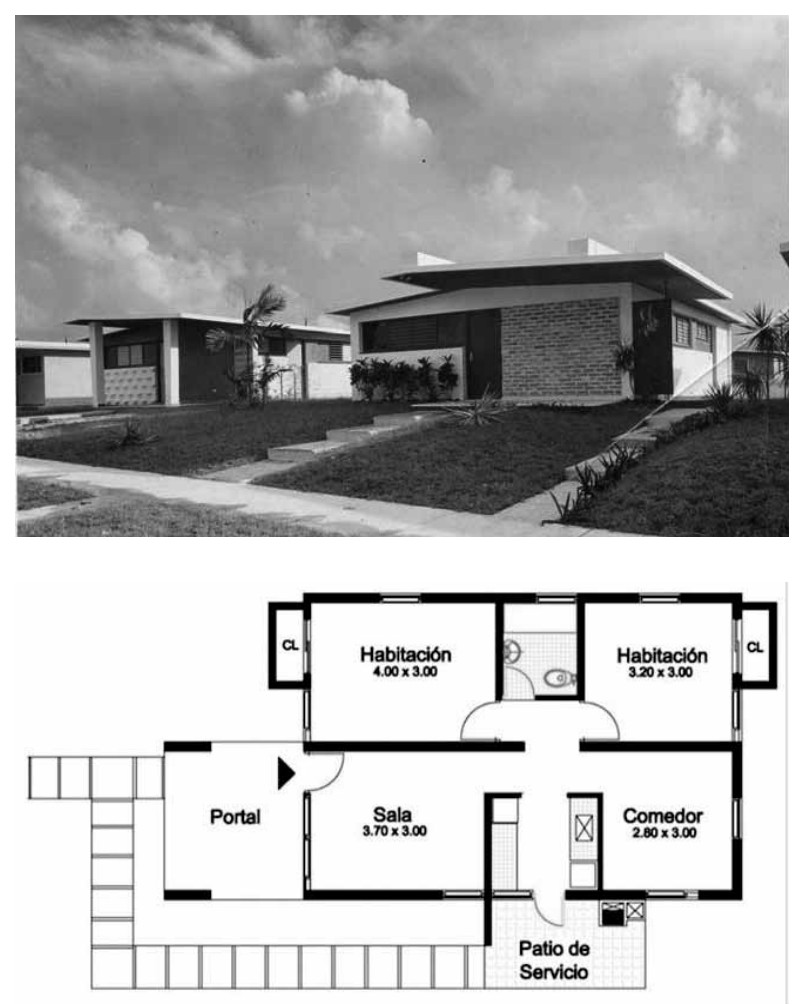

C-2H-2. Área: $74.71 \mathrm{M}^{2}$

Fuente: Departamento de Divulgación del INAV. Fototeca del Nacional de Cuba. comodidades de una vivienda según el modelo, rodeadas de jardín y siempre con un portal. Esta amplia variedad fue pensada también para una pluralidad de ingresos económicos que le permitiera a cada usuario seleccionar el modelo según su precio. La sabia combinación de varios modelos en un mismo frente de calle impidió que la monotonía se adueñase de la imagen urbana (figura 3)

En los repartos de La Habana se ejecutaron 46 modelos, que variaron no sólo por su superficie y estándar, sino también por diferenciarse en su expresión volumétrica, dada por la ubicación de los locales, inclinación de sus cubiertas, la disposición de los vanos, la incorporación de carpoch $^{59}$ en el frente o en los laterales. Emplearon revestimientos de ladrillos, piezas cerámicas y bloques a vista, algunas incorporaron lucetas de colores y celosías para filtrar o tamizar la luz solar. Interiormente se manejó muy bien la privacidad de las áreas íntimas, habitaciones y baños y se caracterizan por ser ventiladas y espaciosas.

Desde los modelos más sencillos hasta los llamativos en los repartos Residencial INAV y Vía Túnel, existe un cuidadoso gusto por la limpieza de las soluciones estructurales y formales que resume lo

59 Car-poch o carport: A diferencia del garaje techado y cerrado con llave para guardar el auto, el carpoch es un espacio para el estacionamiento de autos que pertenece a la vivienda, puede ser techado o descubierto y se puede encontrar en el frente o en un lateral de la vivienda. Es un anglicismo que se utiliza mucho en Cuba para definir este espacio. 
TABLA 3. LEVANTAMIENTO DE LAS VIVIENDAS POR REPARTOS EN LA HABANA.

\begin{tabular}{llll}
\hline$N^{0}$ & Reparto (1959-1960) & Cantidad de modelos & Cantidad de viviendas construidas \\
\hline 1 & Calixto Sánchez (Aéreo) & 6 & 169 \\
\hline 2 & Sergio González, el Trigal & 1 & 140 \\
\hline 3 & Roberto Negrín, Ampl. Del Wajay & 6 & 320 \\
\hline 4 & Juan Manuel Márquez & 16 & 143 \\
\hline 5 & Eduardo Chibas & 9 & 306 \\
\hline 6 & Antonio Guiteras & 8 & 203 \\
\hline 7 & Capri & 7 & 290 \\
\hline 8 & Eléctrico & 8 & 138 \\
\hline 9 & Residencial INAV, Wajay & 14 & 34 \\
\hline 10 & Residencial Vía Túnel & 14 & 39 \\
\hline
\end{tabular}

Fuente: Elaboración propia a partir de INAV, 1962.

mejor del Movimiento Moderno cubano representado de una manera digna y creativa. Muy destacadas dentro de la labor proyectual de estas viviendas por la cantidad de modelos y el excelente diseño de ellos estuvieron las arquitectas Margot del Pozo Seiglie y Heradia Hurtado de Mendoza.

\section{CONJUNTOS DE EDIFICIOS MULTIFAMILIARES}

Los edificios de apartamentos no se quedaron atrás, pues en los 22 modelos de edificios típicos (edificios bajos) que existen se manejaron acertados criterios climáticos de orientación, y disposición de los locales y accesos. Los conjuntos se ubicaron en grandes espacios yermos que existían en la ciudad, muchos de los cuales eran de geometría bastante irregular. Esto condicionó que algunos edificios que quedaban en la profundidad de los lotes no se integraran adecuadamente a la trama urbana y hubiera que acceder a ellos a través de vías o caminos. Los edificios no sobrepasan la altura de los cuatro niveles lo que permite una coherencia con el contexto circundante. Las cajas de escaleras se convierten en volúmenes articuladores las cuales en la mayoría de los modelos se expresan de forma diferente, semi exentas, adosadas, o ligeramente sobresalientes del resto del bloque de apartamentos, de manera que se convierten en prismas referenciales de fuerte impacto visual al coronarse con los depósitos de agua, contrastando con la regularidad de los volúmenes. 

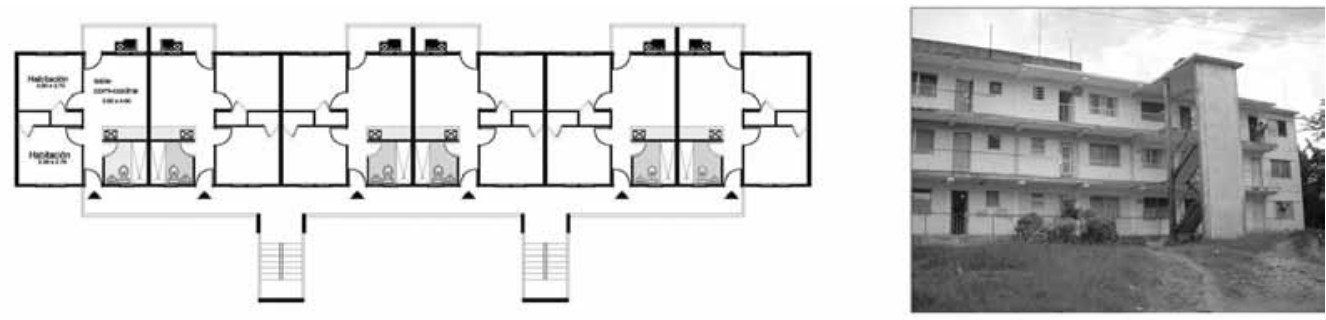

MODELO A. Área de los apartamentos: $42 \mathrm{M}^{2}$
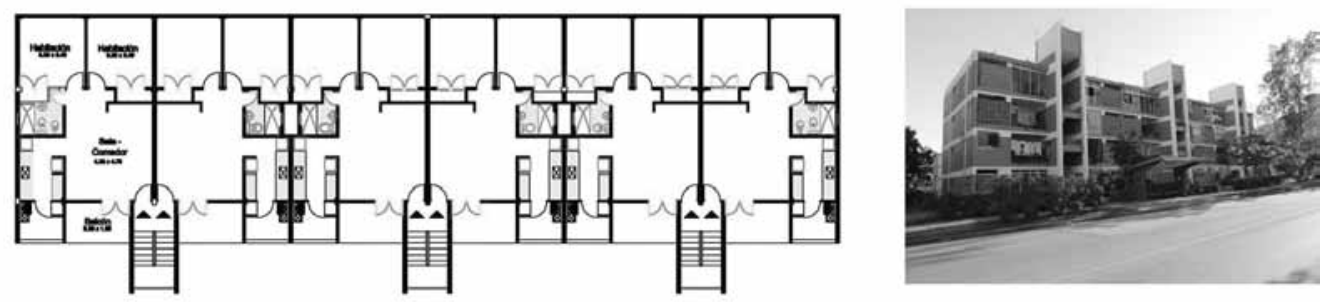

MODELO MH-5. Área de los apartamentos: $68 \mathrm{M}^{2}$
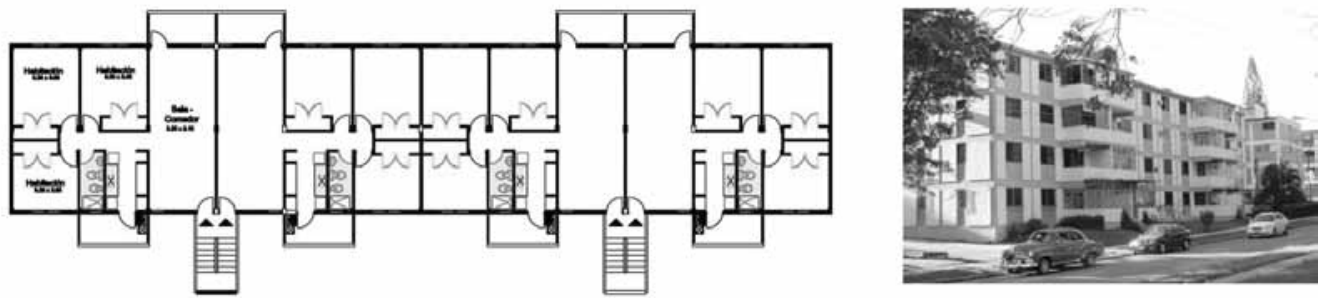

MODELO MH-16(2-A). Área de los apartamentos: $92 \mathrm{M}^{2}$
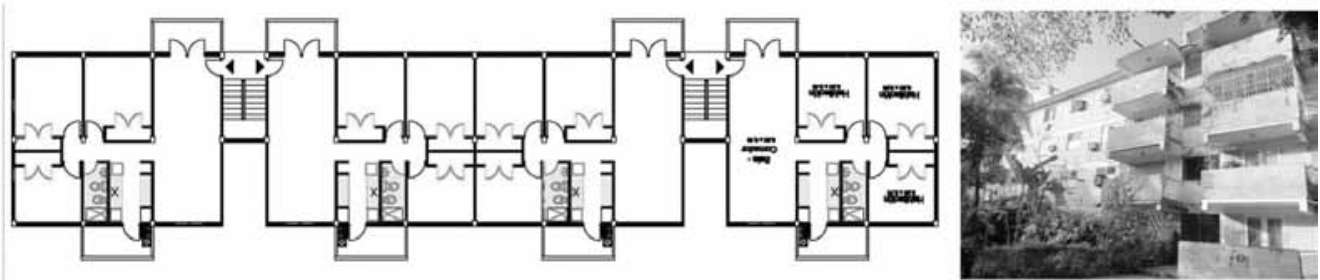

MODELO MH-17(2-B). Área de los apartamentos: $92 \mathrm{M}^{2}$

Fuente: Elaboración propia a partir de los planos originales. 
FIGURA 5. UNIDAD VECINAL N0.1 CAMILO CIENFUEGOS, EN LA HABANA DEL ESTE.

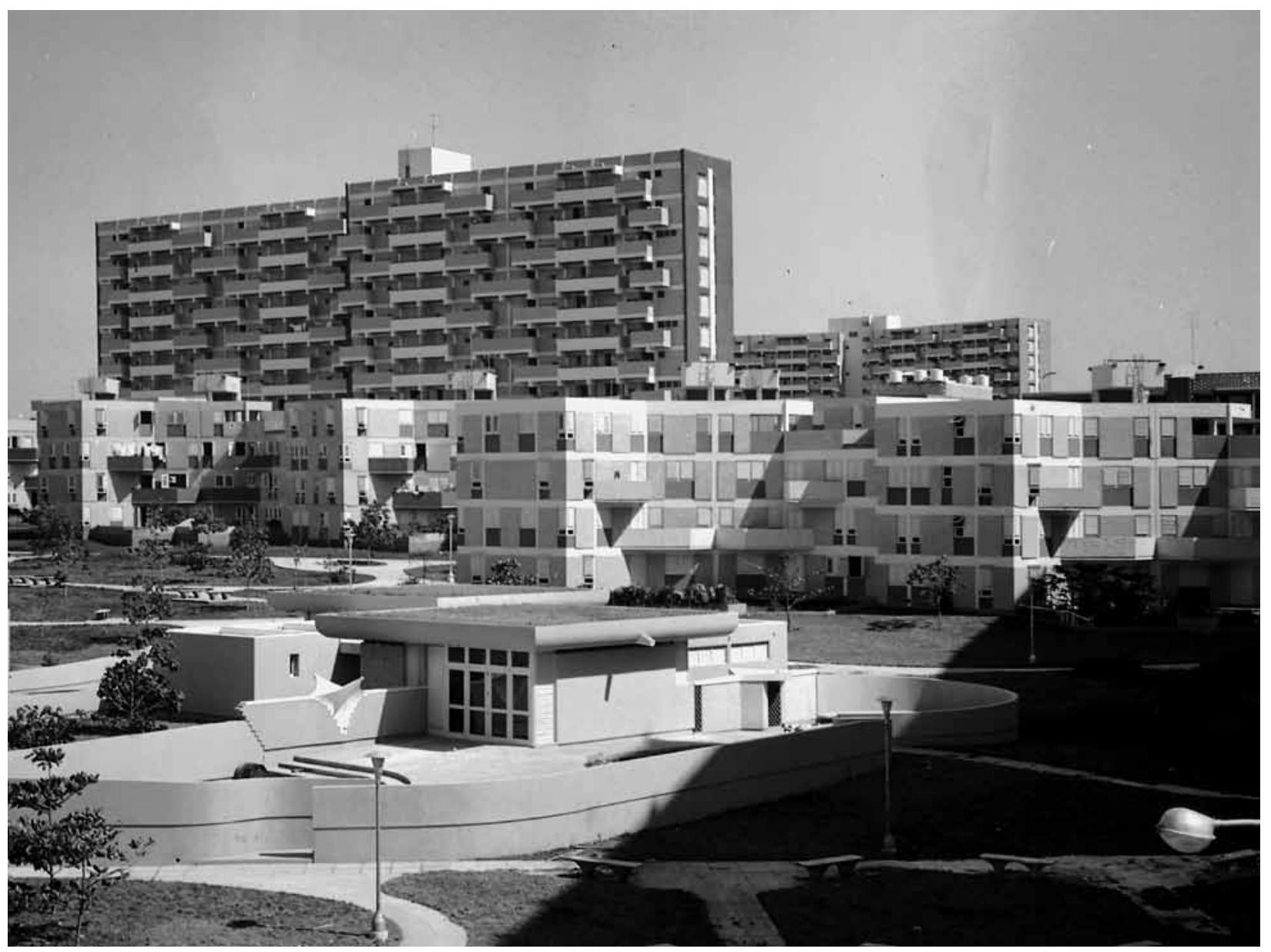

Fuente: Departamento de Divulgación del INAV. Fototeca del Archivo Nacional de Cuba. 
Por lo general los modelos de apartamentos no varían mucho, sin embargo, desde el punto de vista espacial son amplios y ventilados, el espacio de sala comedor siempre se vincula con la terraza o el balcón. La estructura de los edificios se expresa con claridad, definiendo una retícula en que la edificación no se cierra nunca en el plano de fachada, sino que se retranquea generando terrazas y una amplia gama de cierres con celosías que forman diferentes composiciones, a la vez que garantizan la necesaria ventilación cruzada de los apartamentos (figura 4).

\section{“LA CIUDAD DEL PUEBLO"60}

Mención aparte merece la conocida Unidad Vecinal nro. 1 de La Habana del Este, actual "Ciudad Camilo Cienfuegos”, la obra urbanística más importante llevada a cabo por el INAV, proyectada en zona de expansión de la ciudad, -la nueva Habana separada por la bahía-. A poco más de $2 \mathrm{~km}$ de la ciudad se erigió esta obra en una área de 320 $000 \mathrm{~m}^{2}{ }^{61}$, limitado al norte con el litoral costero y por el sur con la Avenida Monumental. Contrapuesta a los esquemas heredados, esta Unidad Vecinal representó el modelo alternativo -expresión de los nuevos ideales sociales-, a la planificación especulativa de las anteriores propuestas para la misma zona de la firma norteamericana Skidmore,

60 Llamada así a la primera gran obra del INAV reflejada en la prensa de la época.

61 INAV, 1962, p. 177.
Owings \& Merril (SOM) y la del arquitecto italiano Franco Albini en los años cincuenta.

El conjunto fue el primer experimento urbanístico coherente que concretó los preceptos expuestos teóricamente durante años por los arquitectos, a través de las revistas cubanas de arquitectura. También resumió los conocimientos teóricos de los arquitectos cubanos sobre las estructuras urbanas, a partir de las principales tendencias vigentes en la década de los años 50 y de principios esenciales del urbanismo contemporáneo aplicados en experiencias internacionales: la unidad vecinal de Clarence Perry en Estados Unidos, las New Towns británicas, las ciudades satélites escandinavas y las experiencias realizadas, a partir de la Segunda Guerra Mundial, en los países socialistas (figura 5$)^{62}$.

El diseño se basó en la supermanzana que garantizaba la protección de los niños y de los residentes en general, e incluía todos los servicios necesarios para que la población no tuviera que salir del área a resolver las necesidades en un radio de acción de $150 \mathrm{~m}$. La Unidad posee 1.306 apartamentos para una población de 7.836 personas, distribuidas en cincuenta y un edificios de cuatro plantas de veinte modelos y siete de once plantas de tres modelos diferentes ${ }^{63}$. Todos los tipos de viviendas constan de sala-comedor, cocina, amplios patios

\section{Segre, 1979, p. 55.}

63 INAV, 1962, p. 177. 
de servicio, terraza y un número variable de 2, 3 o 4 habitaciones según el tipo de apartamento.

Se logró un equilibrio en la alternancia entre edificios altos y bajos, zonas verdes que separa las viviendas de las vías de circulación; jerarquización y diferenciación del sistema vías-peatones y vehículos-estructuración de los diversos niveles de servicios, desde la unidad residencial básica hasta el centro comunitario.

Como director técnico al frente de la obra estuvo el arquitecto Roberto Carrazana y participaron en el equipo entre otros, los arquitectos: Hugo D’Acosta Calheiros, Mercedes Álvarez, Ana Vega, Manuel Rubio, Mario González Sedeño y Reinaldo Estevez, se sumaron además un grupo de estudiantes de arquitectura que después se destacarían en la profesión como Mario Coyula. En seiscientos sesenta y siete días de trabajo (abril de 1959 a noviembre de 1961) se terminó la obra, construyendo a un ritmo de dos casas por día. Fue un modelo integral de vivienda concebido como hábitat integrador, nunca como ciudad dormitorio. Los costos de inversión inicial dieron lugar a un ahorro sustancial a largo plazo.

Por ser una de las primeras obras que realizó la Revolución, capaz de reunir los valores estéticos y de mayor complejidad de la arquitectura y el urbanismo contemporáneos, la Unidad se declaró
Monumento Nacional por la Resolución No. 134, del 23 de abril de 1996 por la Comisión Nacional de Monumentos ${ }^{64}$.

\section{EDIFICIOS AISLADOS}

Una alta coherencia adquieren excepcionalmente algunos edificios aislados y atípicos adaptados según el lugar de emplazamiento, los cuales también poseen valores estético-formales que los hacen destacados en la trama urbana.

El edificio Ñico López construido entre 1959 y 1960 ubicado en el Vedado, fue proyectado por los arquitectos Modesto Campos y Mario González Sedeño ${ }^{65}$. Posee un basamento destinado a garaje con una capacidad para veinte autos, encima una planta baja de uso común para juego de niños, vestíbulo de elevadores y escalera, y seguidamente le sigue la torre de apartamentos de 12 pisos con un total de 49 apartamentos. Su expresión volumétrica mantuvo la parquedad formal y ortodoxa de algunas de las torres especulativas del Vedado, integrándose coherentemente en un entorno con construcciones similares a su altura (figura 6).

Otro ejemplo son los bloques residenciales en el reparto Querejeta, actual municipio Playa. Son tres bloques de 13 apartamentos cada uno, con una planta baja donde existen tres viviendas y un

64 Unidad Vecinal No.1..., 1996

65 Entrevista a Mario González, 2006, p. 13-14. 
FIGURA 6. EDIFICIO DE APARTAMENTOS “ÑICO LÓPEZ”. CALLE 2 E/ LÍNEA Y 11, VEDADO. PLAZA DE LA REVOLUCIÓN
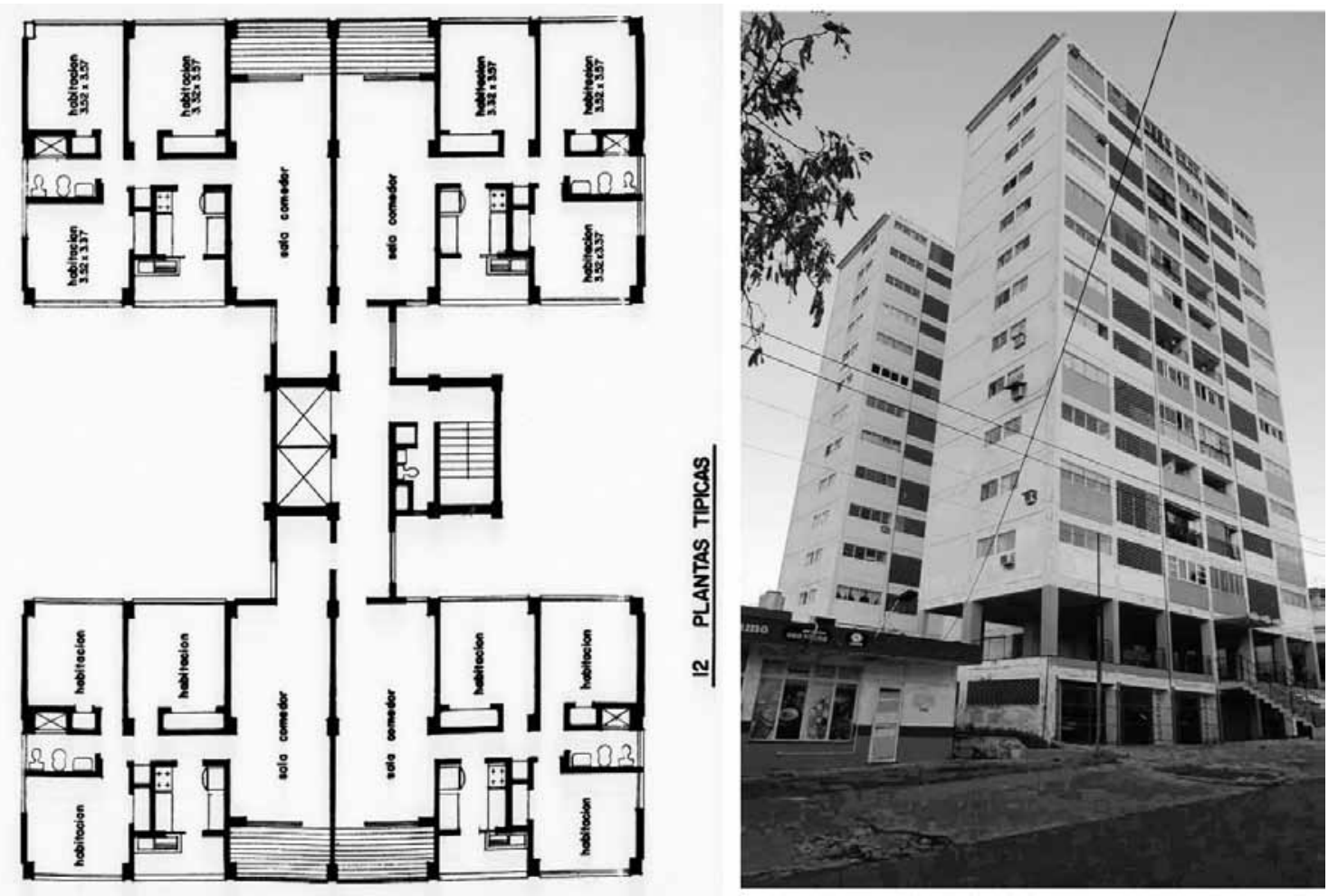

Foto: Autores 


\section{FIGURA 7: EDIFICIO EN CALLE PANORAMA ENTRE CONILL Y TULIPÁN}

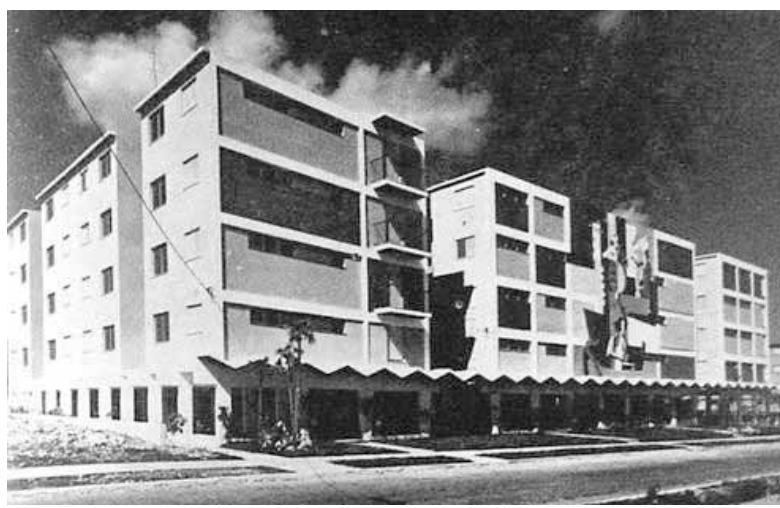

Fuente: Entrega de viviendas..., 1960.

espacio libre destinado a estacionamiento y área de recreo. Las tres plantas típicas tienen doce apartamentos, cuatro por bloque, para un total de $39^{66}$. Cada apartamento consta de terraza, sala-comedor, dos habitaciones con closets, baño, cocina y patio de servicio. En este conjunto de viviendas fueron empleados diferentes materiales y tecnologías constructivas principalmente el hormigón armado para los elementos estructurales (originalmente a vista en algunos puntos): pavimentos de terrazo que enmarcan el acceso a los núcleos de circulaciones verticales y escalones de igual tratamiento, losetas prefabricadas en los interiores de los apartamentos y celosías formadas por bloques de hormigón. Muy similar es el edificio "Gerardo Abreu Fontán", en el reparto Nuevo Vedado, de cuatro bloques de cinco plantas, cuatro de ellas típicas y una planta baja. Posee un total de 65 apartamentos compuesto por sala-comedor, portal dos habitaciones, closets, baño, cocina y patio de servicio. En tanto en la planta baja se previó un local destinado a Kindergarten, un apartamento para el encargado del edificio y demás espacios libres de circulación y esparcimiento (figura 7)

\section{Consideraciones finales}

\section{LA SIGNIFICACIÓN DE LA LABOR DEL INAV}

A partir de 1930 el enfoque para tratar a la vivienda social en muchas de las experiencias se basó en el concepto de la unidad vecinal. La difusión universal de los principios y modelos del urbanismo moderno permitió que se implantaran o impusieran en distintos contextos sociales y culturales. América Latina fue uno de los campos donde se desarrollaron alternativas particulares, adaptadas a la situación de cada país.

La obra del INAV materializó muchas de las aspiraciones de los arquitectos cubanos sobre la vivienda

INAV, 1962, p. 463. 
social que se habían teorizado y divulgado en publicaciones, concursos y eventos nacionales y regionales. Socialmente tendió a la estabilidad de la familia, al pretender que cada ciudadano llegara a ser propietario de su casa. Bajo el lema: "una casa propia para cada familia cubana" llevó a desplegar acciones de un extremo a otro de toda la nación, en beneficio de miles de ciudadanos.

La alta demanda de vivienda para una población en continuo aumento, los equipos importados para los edificios altos, la readecuación de los planes de expansión de la ciudad, detuvieron la continuación de esta experiencia. Por otra parte el INAV había perdido a sus dos guías fundamentales: el arquitecto Cesáreo Fernández, Coordinador Nacional de las obras, falleció en octubre de 1959 y la asignación a Pastorita de otras tareas debilitaron la constancia y el ritmo de las obras. Por ese entonces la prefabricación masiva se vio como la solución ideal para satisfacer los futuros planes habitacionales, los criterios e índices técnicos y económicos se convirtieron en paradigmas que asumió la arquitectura y el urbanismo según avanzó la década de los años sesenta.

La experiencia del INAV se desarrolló con altos grados de libertad en el diseño, justificados por la utilización de los sistemas constructivos artesanales, y por un excelente equipo de arquitectos que supieron asimilar la influencia externa en cuanto a principios de diseño urbano y arquitectónico y fusionarlos con la especificidad de la arquitectura cubana, dándole continuidad a lo mejor que se venía haciendo anteriormente.

Uno de los principales aportes urbanísticos del INAV radicó en la concepción integral de los asentamientos habitacionales que concibió por todo el país, incorporando los servicios comunales para el pleno desarrollo humano (mercados, escuelas, centros recreativos, de salud, y parques, todos de una excelente calidad en sus diseños). Dentro de sus aportes arquitectónicos se destaca la amplia variedad de modelos y estándares de las viviendas y apartamentos, pensada también para una pluralidad de ingresos económicos que le permitiera a cada persona seleccionar el modelo según su precio.

El paso del tiempo ha demostrado la validez de las obras, la calidad de su diseño y ejecución. El $100 \%$ de los conjunto de edificios multifamiliares y de los edificios aislados hechos en La Habana se mantienen íntegramente y en buen estado de conservación. Sin embargo muchas de las viviendas individuales en los repartos han sufrido modificaciones algunas radicales e irreversibles.

La obra de Pastorita fue una experiencia única en la historia de la arquitectura y el urbanismo cubano como expresión de la voluntad del Estado para garantizar una vivienda digna a sus ciudadanos. La trascendencia en el tiempo del quehacer de este instituto fue el resultado de la alta creatividad 
proyectual de sus autores, de la estructura institucional articulada nacionalmente, de la coherencia de la gestión y acción de los agentes involucrados, así como la estructuración de un cuerpo técnico unificado, capaz de desarrollar mediante técnicas constructivas tradicionales una producción masiva y de alta calidad.

A sus valores estéticos y arquitectónicos se suman sus valores sociales y culturales arraigados en la memoria histórica de sus habitantes. Las casas de Pastorita contribuyeron a conformar una parte de la geografía social de la ciudad y de su paisaje residencial. Sirva entonces este primer acercamiento sobre el tema para reconocer este patrimonio moderno habitacional cubano del siglo XX.

\section{Bibliografía}

AAVV. El edificio de apartamentos en Cuba. Facultad de Arquitectura, ISPJAE. 2007.

ABOY, Rosa. La vivienda social en Argentina. El caso de Buenos Aires, 1930-1960. En: SAMBRICIO, Carlos, ed. Ciudad y vivienda en América Latina 1930-1960. Madrid, Lampreave. 2012.

ANDA ALANÍZ, Enrique X. de. Vivienda social en la ciudad de México durante el periodo 1945-1965. En: SAMBRICIO, Carlos, ed. Ciudad y vivienda en América Latina 1930-1960. Madrid, Lampreave. 2012.
BELL LARA, José. Documentos de la Revolución Cubana 1959. La Habana, Editorial de Ciencias Sociales. 2006.

BENS ARRARTE, José M. La obra de la New York City Housing Autority. Arquitectura. 17(206): 383-397, septiembre 1950.

BONDUKI, Nabil. Vivienda social en la vanguardia de la arquitectura moderna en Brasil. En: SAMBRICIO, Carlos, ed. Ciudad y vivienda en América Latina 1930-1960. Madrid, Lampreave. 2012. p. $141-167$

CASTRO RUZ, Fidel. Discurso pronunciado con motivo de la celebración del primer aniversario del Instituto Nacional de Ahorro y Viviendas, el 20 de febrero de 1960. [En línea]. Cuba.cu. [Fecha de consulta: 23 marzo 2013]. Disponible en: http:// www.cuba.cu/gobierno/discursos/1960/esp/ f200260e.html

---- Discurso pronunciado con motivo de la inauguración del seminternado de primaria "Juan Manuel Márquez", en Boca de Jaruco, el 15 de marzo de 1968. [En línea]. Cuba.cu. 1968. [Fecha de consulta: 5 septiembre 2014]. Disponible en: http:// www.cuba.cu/gobierno/discursos/1968/esp/ f150368e.html

CONCURSO de ante-proyecto edificio monumental, reparto Alamar. Arquitectura. (320): 144-150, marzo 1960.

COYULA COWLEY, Mario. La Habana que va conmigo. La Habana, Editorial Letras Cubanas. 2002. 
CREACIÓN del Banco Privado Interamericano de Fomento a la vivienda de interés social. Arquitectura. 23(267): 481-484, octubre 1955.

CUBA: la arquitectura en los países en vías de desarroIlo. Séptimo Congreso de la Unión Internacional de Arquitectos. La Habana, UIA. 1963.

DIEZ-PASTOR, Ma Concepción. La vivienda mínima en España: primer paso del debate sobre la vivienda social. [En línea]. Scripta Nova. Revista electrónica de geografía y ciencias sociales. 7(146), agosto de 2003. [Fecha de consulta: 8 junio 2014]. Disponible en: http://www.ub.es/geocrit/sn/sn146(023).htm

EL INAV aprueba decreto que suspende los planes de regalos de viviendas. Bohemia. 51(24): 51, junio 1959.

ENTREGA de viviendas por el Instituto Nacional de Ahorro y Vivienda (INAV). Arquitectura-Cuba. (318): 41-47, enero 1960.

ENTREVISTA a Mario González. El edificio alto como acento. Docomomo Cuba. 2(6): 13-14, diciembre 2006.

ESTÉVEZ CURBELO, Reynaldo. Arquitectos, reforma urbana y vivienda. Arquitectura-Cuba. (309-310): 154, abril 1959.

FERNÁNDEZ FERRER, Héctor R., dir. Pastorita. [audiovisuall. La Habana, Productora de Audiovisuales de la Oficina del Historiador de la ciudad de La Habana y la Alianza Martiana de Miami. 2011.
GELABERT, Dayra. Vivienda progresiva en ciudad de La Habana. Bases para su desarrollo. La Habana, ISPJAE. 2010. Tesis de maestría.

GÓMEZ DÍAZ, Francisco. De Forestier a Sert: ciudad y arquitectura en La Habana (1925-1960). Madrid, Abada editores. 2008.

GONZÁLEZ COURET, Dania. Arquitectura culta vs. arquitectura popular en la vivienda. Arquitectura y Urbanismo. 27 (2-3): 57-62, 2006.

GUERRA VILABOY, Sergio. Breve historia de América Latina. La Habana, Ciencias Sociales. 2010.

HIDALG0, Rodrigo. Vivienda social y espacio urbano en Santiago de Chile. Una mirada retrospectiva a la acción del Estado en las primeras décadas del Siglo XX. [En línea]. EURE. 28(83): 83-106, mayo 2002. ISSN 0250-7161. Disponible en: http://dx.doi. org/10.4067/S0250-71612002008300006

INAV. Presencia del INAV en la Revolución Cubana. 1962.

LEYES del Gobierno Provisional de la Revolución (III). La Habana, Editorial Lex. 1959.

LÓPEZ DÍAZ, Jesús. La relevancia de la vivienda social en el origen de la arquitectura contemporánea. [En línea]. Espacio, Tiempo y Forma serie vii, historia del arte. (16), 2003. Disponible en: http://revistas.uned.es/index.php/ETFVII/article/ view/2405

MEZA, Beatriz. Cerro piloto: el plan extraordinario de vivienda para Caracas, 1954. [En línea]. Tecnología y Construcción. 25(2): 17-32, agosto 
2009. ISSN 0798-9601 [Fecha de consulta: julio 2014]. Disponible en: http://www2.scielo.org. ve/scielo.php?script=sci_arttext\&pid=S0798 96012009000200003\&lng=es\&nrm=i

MINISTERIOS y oficinas especializadas en vivienda y urbanismo. Arquitectura. 23(267): 471, octubre 1955.

PEÑATE DÍAZ, Florencia. La vivienda del pobre en La Habana de la Republica. Arquitectura y Urbanismo. 32(2): 36, 2011.

PÉREZ PÉREZ, Ileana C. La lotería en Cuba. Madrid, Gráficas Navagraf. 1995.

RAPOSO, Alfonso. La vivienda social de la CORVI. Un otro patrimonio. [En línea]. Boletín INVI. 14(37):19-40, agosto 1999. Disponible en: http:// revistainvi.uchile.cl/index.php/INVI/article/ view/247/966

REPÚBLICA de Cuba. Comisión Nacional de Viviendas. Un año de labor. Habana, Cuba, Artes Gráficas. 1954.

SAMBRICIO, Carlos, ed. Ciudad y vivienda en América Latina 1930-1960. Madrid, Lampreave. 2012. ISBN 9788461600533.

SEGRE, Roberto. Diez años de arquitectura en Cuba revolucionaria. La Habana, Ediciones Unión. 1970.

---- La vivienda en Cuba: república y revolución. La Habana, Editorial 13 de marzo. 1979.

Arquitectura y urbanismo de la Revolución Cubana. La Habana, Editorial Pueblo y Educación. 1989.

120 revista invi № 84 / Agosto 2015 / Volumen № 30: 89-120
UNIDAD vecinal No.1 Ciudad Camilo Cienfuegos. [En línea]. Portal del Consejo Nacional de Patrimonio Cultural. 1996. Disponible en: http://www.cnpc. cult.cu/patrimonio/184.

ZARDOYA, María V. Por unas casas dignas. La vivienda social en La Habana, 1930-1962. En: SAMBRICIO, Carlos, ed. Ciudad y vivienda en América Latina 1930-1960. Madrid, Lampreave. 2012. 